\title{
Strategic entrepreneurship and knowledge spillovers: spatial and aspatial perspectives
}

\author{
Sam Tavassoli ${ }^{1,2}$ (D) Lars Bengtsson $^{3}$. \\ Charlie Karlsson ${ }^{4,5,6}$
}

Published online: 3 August 2016

(C) The Author(s) 2016. This article is published with open access at Springerlink.com

\begin{abstract}
The literature in the Strategic Entrepreneurship (SE) is increasingly embracing the concept and implications of knowledge spillovers. In this paper, we add to the theoretical repertoire on SE and knowledge spillovers by investigating the types of knowledge spillovers and what they imply for various dimensions of SE. On the one hand, we distinguish between spatial and aspatial knowledge spillovers. On the other hand, we distinguish between three dimensions of SE, i.e. inputs, resource orchestration, and output. Finally, we conceptually link the various types of knowledge spillovers and dimensions of SE and discuss the implications. Doing so, we argue that spatial knowledge spillovers (inter-firm) has received the major attention in previous research in increasing the amount of 'inputs' dimension of SE, while the aspatial knowledge (either inter-regional or intrafirm) has been relatively neglected not only for 'inputs', but also for 'resource orchestration' dimension. At the end, the paper provides suggestions for future research.
\end{abstract}

Sam Tavassoli

sam.tavassoli@circle.lu.se

Lars Bengtsson

lars.bengtsson@iml.lth.se

Charlie Karlsson

charlie.karlsson@ju.se

1 Centre for Innovation, Research and Competence in the Learning Economy (CIRCLE), Lund University, Box 117, 22100 Lund, PO, Sweden

2 School of Management, RMITUniversity, Melbourne, VIC 3000, Australia

3 Faculty of Engineering, Department of Industrial Management and Logistics, Lund University, Box 118, 22100 Lund, PO, Sweden

4 Centre of Excellence for Science and Innovation Studies (CESIS), KTH, Stockholm, Sweden

5 Jönköping International Business School, Jönköping, Sweden

6 Blekinge Institute of Technology, Karlskrona, Sweden 
Keywords Strategic entrepreneurship $\cdot$ Knowledge spillovers $\cdot$ Spatial $\cdot$ Aspatial

\section{Introduction}

There has been an emerging literature in the topic of Strategic Entrepreneurship (SE) since the beginning of twenty-first century pioneered by both management and economics scholars (Hitt et al. 2001; Ireland et al. 2001; Kuratko and Audretsch, 2009). In this vein, a new interest is to analyse the role of knowledge spillovers for strategic entrepreneurship (Agarwal et al. 2007, 2010). A limitation with this literature is that it does not explicitly acknowledge that most of the knowledge spillovers are a "spatial" and geographical phenomenon, i.e. spatial inter-firm knowledge spillovers. Such spatial aspect should be at work, since the knowledge spillovers occur between firms and other economic agents that have a specific location and geographical proximity to each other. Such a spatially bounded knowledge spillovers generates a peculiar issue, since the transfer of knowledge is often a slow and complicated process, which is affected by the frictions of geographical space. Moreover, in knowledge spillover literature itself, less attention has been devoted to the "aspatial" knowledge spillovers, which could be intra-firm or inter-regional spillovers, let alone the implication of aspatial knowledge spillovers for SE.

The aim of this paper is to combine the theoretical perspectives of knowledge spillover and SE in order to identify research gaps and implications for further research in SE. More specifically, we combine the perspective of knowledge spillovers in terms of its geographical reach (spatial vs. aspatial) with the three dimensions of SE, i.e. inputs, resource orchestration processes, and output of SE (Hitt et al. 2011). By combining the two theoretical perspectives we increase the interpretative repertoire (Alvesson and Kärreman 2007) of SE research using the theoretical lens of knowledge spillover. The result is a framework highlighting the current attention in SE research on spatial knowledge spillover as the most prominent type of knowledge spillovers and the relative lack of SE research studying aspatial knowledge spillovers. We conclude by advocating the need for further attention and research to aspatial knowledge spillover in all dimensions of SE.

The rest of the paper is as follows. Next section provides an overview on state-of-the art on newly emerging literature on SE by discussing three dimensions of SE. Then we will provide a discussion on various aspects of knowledge spillover, by distinguishing between spatial and aspatial types of knowledge spillovers. Next we will link the previous two sections by providing a framework of current SE research using a theoretical lens of knowledge spillovers and discusses implications of different types of knowledge spillovers for the three dimensions of SE. Finally, the last section concludes and provides suggestions for further research.

\section{Strategic entrepreneurship}

Strategic entrepreneurship (SE) focuses on the complementarities of strategic management and entrepreneurship (Ireland et al. 2003). Both research disciplines are concerned with value creation (Bruyat and Julien 2001). However, entrepreneurship research has 
been highlighting value creation through opportunity-seeking (e.g., Shane and Venkataraman 2000) and strategic management research value creation through competitive advantage-seeking (e.g., Barney 1991). Moreover, entrepreneurship has foremost been concerned with new venture creation and the growth of small firms and strategic management mostly with large established firms. The concept of SE is thus an attempt to merge the two views of value creation in order to explore "... how do firms create and sustain a competitive advantage while simultaneously identifying and exploiting new opportunities" (Hitt et al. 2011:57). While SE is not specifically about large or small firms, there is an assumption that SE might learn more about how small firms could act more strategically and how large established firms can become more entrepreneurial (Hitt et al. 2011).

$\mathrm{SE}$ is still a young and developing research field. Most research in the field emanate after the call for integrating the two research areas in a series of papers by Hitt and Ireland and associates (Hitt et al. 2001; Ireland et al. 2001). While the intersection of strategy and entrepreneurship had interested strategy and entrepreneurship researchers long before this, e.g., Mintzberg and Waters (1982)'s entrepreneurial strategy; Meyer \& Heppard (2000)'s entrepreneurship as strategy; and the whole field of corporate entrepreneurship (Burgelman 1983); more systematic attention towards this field developed after 2001. Some of the more influential researchers in the field are Hitt and Ireland and their associates who have published several conceptual papers in the field mapping out the domain of SE. In their input-process-output model of SE, Hitt et al. (2011) identify three dimensions of SE-research: resource/input factors, resource orchestration processes and outputs. Using these three dimensions as the basis, we will devote the remainder of this section to provide an overview of the state-of-the art in the SE field.

\section{Resources/inputs affecting SE}

The external environment affects the firm's and the individual abilities to discover, create, and exploit opportunities in various ways. Ultimately it affects long-term survival (Hannan and Freeman 1989), firm performance (Keats and Hitt 1988) and firms' development paths (Winter 2005). From an SE perspective environmental munificence, dynamism and interconnectedness are the most important environmental factors (Hitt et al. 2011).

Environmental munificence makes resources relatively easy to acquire as well as identifying and exploiting opportunities. Firms seek for environmental munificence in order to facilitate survival and growth. SE researchers have paid attention to environmental munificence in the form of knowledge spillovers (Agarwal et al. 2010:271), defining it as "...the external benefits from creation of knowledge that accrue to parties other than the creator, occur at multiple levels of analysis, be it within or across organization and networks." The knowledge spillover view offers a lens to explain the causes and consequences why firms fail or succeed to create and appropriate value from knowledge investments (Agarwal et al. 2007). This is one of the dominant research areas within SE and we will highlight this research in the subsequent sections of the paper.

Some environments are inherently dynamic and thereby also uncertain. Environmental dynamism is associated with new venture creation (Aldrich 2000). The ability to operate in dynamic environments, using dynamic capabilities (Eisenhardt and Martin 
2000) may be a source of competitive advantage (Teece, 2007). Some firms use collaborative strategies, and develop alliance capabilities (Larsson et al. 1998) to access resources from partners and bundle them in new combinations to exploit opportunities. SE research here includes Ketchen et al. (2007) study of collaborative innovation where small and large firms share knowledge and expertise in order to exploit opportunities. On a cluster level there are studies demonstrating increased firm performance for firms collaborating in local and external networks in the footwear (Boschma and Ter Wal 2007) and wine industry (Li et al., 2015).

The combination of knowledge spillover and dynamism is explored in a longitudinal study of the telecommunications-industry by Yang and Steensma (2014), where they find that knowledge originator firms are prone to look for guidance into new knowledge domains from knowledge recipient firms in dynamic and highly competitive environments. However, in high-growth environments firms are less prone to look for guidance from recipient firms and pursue more risky strategies which are balanced by the munificence of the high-growth environment.

Another type of input to SE is organizational resources (Hitt et al. 2011) such as culture and leadership. Entrepreneurial leadership is to influence others to engage in a simultaneous opportunity-seeking and advantage-seeking behavior (Covin and Slevin 2002). Shepherd et al. (2009) have shown how leaders' entrepreneurial mindset and the organizational culture amplify each other in positive spirals. Top management teams' shared leadership has been demonstrated to benefit organizational ambidexterity, i.e., the simultaneous pursuit to explore and exploit (Mihalache et al., 2014).

Traditionally entrepreneurship research has focused on the individual and his/her resources (Shane and Venkataraman 2000). Human capital in SE is the individual's knowledge, motivation, abilities and skills to perform in order to exploit an opportunity and achieve an advantage. In particular the individuals' idiosyncratic capital is of interest as it might be a source of competitive advantage such as the entrepreneurial mindset (McGrath and MacMillan 2000) and creativity (Ireland et al. 2003). Entrepreneurial leader with high self-efficacy has been associated with increased firm performance (Baum and Locke 2004). A highly educated CEO is a relatively more valuable resource for a small firm than for a large firm as they might have more discretion in small firms and is a more unique resource compared to other small firms (Miller et al., 2015). An individual's social capital, such as reputation and extensive social networks within specific contexts, has been shown to have beneficial outcomes both for new ventures and established firms (Baron and Tang 2009; Kleinbaum and Tushman 2007; Light and Dana 2013). Some studies also account for both human and social capital. Grichnik et al., (2014) show how nascent entrepreneurs with higher levels of social and human capital make them able to use more bootstrapping activities in order to acquire resources to their intended start-up. Moreover, social capital and social competence have been shown to overcome the gap between technical business ideas and market launch (Tocher et al. 2015).

\section{Resource orchestration processes}

Gaining access to valuable, rare and inimitable resources is not enough to achieve competitive advantage, they also need to be efficiently organized and orchestrated (Barney 1991, Helfat et al., 2007). Two such orchestration processes are 
bundling and leveraging (Hitt et al. 2011). As resources and capabilities are often formed within functions such as manufacturing and IT, bundling means combining these resources and capabilities in order to identify and exploit new opportunities as well as seeking competitive advantages. Leveraging means actions to mobilize, coordinate and deploy capabilities in order to achieve competitive advantages. In practice these two processes are hard to differentiate as they both include the forming of more complex resource and capability combinations in order to create valuable, rare and hard-to-imitate capabilities as well as increased ability to act on opportunities. As an example Zhang, Wu and Henke (2015) found that a customer firm's boundary spanning capabilities combined with communication capabilities increased supplier firms' willingness to invest in the customer firm. However, all resources are not the same and sometimes may mix badly or require different management skills. It might be relatively easy for experienced managers when leveraging fungible resources such as cash and brands, but more difficult when it comes to more idiosyncratic resources with less fungibility such as talented film directors (Mannor et al., 2015). The capability to bundle and leverage might be thought of as a dynamic capability in the sense that it could be deployed in general to create bundles of resources and deploy them. For instance, Liu et al. (2010) demonstrate that the best-performing internationalizers among Chinese entrepreneurial firms are the ones that have these bundling capabilities in order to meet the requirements of the foreign markets.

\section{Outputs of SE-processes}

In general the assumption in SE is that the final outcome will be a new stable venture or an established firm will experience competitive success by creating customer value (Hitt et al. 2011). These outcomes will be translated to financial wealth for the owners of the firm or venture but also other outcomes are discussed in the SE-literature. For the individual there is increased personal knowledge when starting a firm (Baron and Henry 2010) as well as the enjoyment and pleasure of solving problems and creating something new (von Hippel, 2005). There are also societal benefits from strategic entrepreneurship such as running public services (McGahan et al. 2013). The social role of entrepreneurship includes connecting to societal aims such as quality of life, achieving progress, and enriching human existence as well as economic growth and technological advancement (Zahra and Wright, in press).

However, before reaching such outcomes, more intermediate outcomes on the organizational level are likely to emerge, in particular new technology and innovation (Hitt et al. 2011; Tavassoli and Karlsson 2015a, 2015b; Karlsson and Tavassoli 2016). Creating innovations are vital for many new ventures as well as for established firms to maintain or increase competitiveness. To create novel innovations a firm needs to shift its attention from the present products; processes; organizational and marketing arrangements and/or business model to the future ones (cf. Sood \& Tellis, 2005). Often firms, especially new and small firms, do not have all the required resources and capabilities to create innovations. They need to develop a network of partners and develop capabilities to manage innovation networks (Dodgson et al. 2006). Often new ventures, despite lack of resources, are more creative and entrepreneurial in creating more radical innovations while large and established firms are better at incremental innovations, adding new features to the products or trimming of processes. Thus, a 
solution to this for large firms is to team up with or acquire smaller and more entrepreneurial firms, balancing exploration and exploitation. Acquisitions of or investment in smaller entrepreneurial firms having developed promising new technologies are common in ICT and the pharmaceutical/biotech-sectors. Corporate investors seem to prefer smaller entrepreneurial firms with well-developed innovative capabilities pre-funding compared to private investors (Park and Steensma 2013). However, it is not only about new technology, it could also concern new and better business models. In the electric power industry some large utilities are now teaming up with small entrepreneurial solar energy firms (Ahlgren et al. 2015) mostly to learn about their new business models on the residential electric power markets.

Summarizing this section, SE has emerged as a new research field in the last two decades or so. The intent is to merge the strategic management's and entrepreneurship's view on value creation into an advantage- and opportunity-seeking view of the firm. We have described SE-research domain, in line with the input-output model proposed by Hitt et al. (2011), as focusing on three dimensions: input/resources of SE, resource orchestration of SE and outputs of SE. Moreover, one of the more dominant research streams in SE input/resources is knowledge spillover and how new ventures and established firms succeed or fail to utilize knowledge spillovers in order to identify and exploit opportunities, developing new technologies and innovations, as well as developing competitive advantage. The next section will give an overview of the knowledge spillover research field.

\section{Knowledge spillovers}

In this section, we will portray the anatomy of knowledge spillovers by having a critical literature review on various aspects of knowledge spillovers. We will start by discussing various mechanisms in which knowledge spillovers is transmitted between economic agents. Then we will discuss the sources and recipients of knowledge spillovers more in detail by paying particular attention to geographical reach of knowledge spillovers. This will be done by distinguishing between the spatial (interfirm within a region) knowledge spillovers and aspatial (either intra-firm or interregion) knowledge spillovers respectively. While the literature in knowledge spillover is mostly dominated by spatial knowledge spillovers, we find it useful to have a discussion of aspatial knowledge spillover as well. This is particularly helpful when it comes to implication of knowledge spillover for SE (will be elaborated in later in this paper).

\section{Mechanisms of knowledge spillovers}

Breschi and Lissoni (2001) argue that the mechanisms conveying knowledge spillovers include (i) formal and informal interaction between firms and other economic agents, where the formal interaction is based on an explicit contract, while the informal interaction is based upon an implicit contract, (ii) active knowledge search of firms, and (iii) mobility of firms and individuals, particularly in the form of entrepreneurial spin-offs. The formal and informal interaction between firms and other economic agents can take many forms ranging from transactions of goods and services 
(including R\&D-services) to cooperation in the form of joint ventures and strategic alliances (including R\&D-cooperation) (Ratten and Suseno 2006; Suseno and Ratten 2007).

Informal networking tends to mainly take place at the regional level, and thus knowledge spillovers through this channel tend to be localised (Breschi and Lissoni 2006). It includes the interaction of employees of different firms and other economic agents privately and in social, civic and professional organizations. Since much knowledge is embodied in people, it is natural to assume that knowledge spillovers are partly a function of the interaction between people with the relevant education, skills and experiences. Relations to suppliers and/or customers are also potential channels for knowledge spillovers, which is highlighted by Kline and Rosenberg (1986), who stress the importance of interdependence and dynamic learning across various firms and economic agents within a linkage and feedback model of innovation. Furthermore, trade with goods and services embodying knowledge is a further channel for knowledge spillovers and externalities (Grossman and Helpman 1994; Verspagen 1997).

Formal networking is the prominent mechanism for inter-regional aspatial knowledge spillovers and it is not mainly limited to the regional (Dana 2001). For example, formal networking as in the formal research collaboration tends to take place at both national and international scales (Mckelvey et al. 2003; Ponds et al. 2007; Hoekman et al. 2009; Ratten 2014). Thus, knowledge spillovers form research collaboration that builds upon network formation through link investments which can take place between firms in different regions.

Mobility of economic agents involves the mobility of labour as well as the mobility of firms, which are an important channel for knowledge spillovers (Boschma et al. 2009). One important form of mobility of firms is foreign direct investments (Braunerhjelm and Ekholm 1998). An example of mobility of people is through the mechanism of international 'returnees'. Liu et al. (2010) find that Chinese firms founded by Chinese overseas returnees are more innovative than their domestic counterparts founded by Chinese settled in the country. These returnee firms also have a spillover effect on non-returnee firms. Moreover, there exist several more mechanisms, which support and facilitate the transfer and diffusion of tacit as well as codified knowledge (cf., Arrow 1994) and technology: i) education, ii) seminars, conferences and trade fairs (Karlsson 1988), iii) interactive communication channels (E-mail, the Internet, video conferences, etc.), iv) people specially designated to obtain and disseminate knowledge (e.g. gatekeepers) (cf. Allen 1977), v) knowledge management within and between firms and economic agents, and vi) imitation.

It is important to notice that even if each of these channels can be seen as partly independent of each other, they are often linked to each other in different ways. For instance, according to Archibugi and Coco (2004) international cooperation in both the private and the public sector play an important role for knowledge diffusion. An increasing number of partnerships among firms, universities and public research centres as well as between individual researchers and inventors is a clear indication of the growing importance of collaboration. Collaboration permits the partners to share and acquire the expertise of each other, thus enriching their overall know-how. It often functions as a positive sum game, where the advantages outweigh the disadvantages even if the advantages are not always equally shared among the partners (Archibugi and Lundvall 2001). 
The knowledge spillovers may occur vertically or horizontally. If we start with the former case, where firms interact directly, it is obvious that knowledge may spillover vertically between firms when goods or services are delivered between firms. The knowledge spillover may be due to geographical proximity and then it covers both localization and urbanization economies. Links between firms also facilitate knowledge spillovers. Knowledge may also spillover horizontally between competing firms in geographical proximity of each other. This may be referred to as a Porter externality and corresponds to localization economies (in a specialized cluster) (Porter 1990). Considering the fact that knowledge spillovers to competing firms are unwanted effects for firms in a market economy, hence the clustering of competing firms tells us that there are advantages of agglomeration outweighing the negative effects of knowledge spillovers. Finally, Joint ventures and strategic alliances may give rise to vertical as well as horizontal knowledge spillovers depending upon what firms are involved.

Summarising this section, we can observe that firms may (i) acquire knowledge and support in its development activities by purchasing inputs from knowledge suppliers, (ii) form research, development and innovation links with other firms on a commercial basis, (iii) acquire knowledge as a spillover effect of the ordinary interaction on its transaction links, and/or (iv) get knowledge as a spillover effect when interacting directly or indirectly, intentionally and unintentionally with other firms and economic agents in the own region and in other regions.

\section{Spatial knowledge spillovers}

A critical issue in analysing the role of knowledge spillovers and thus knowledge externalities for regional economic development is the geographic or spatial reach of knowledge spillovers. We have many reasons to believe that knowledge is subject to spatial decay (cf. Henderson 1996). Due to "the tyranny of distance", most human interaction takes place within the functional region and in particular the locality where firms are localized and where people live and often work. The claim that geographical proximity matters for knowledge spillovers between firms is largely supported by the empirical literature (Karlsson and Manduchi 2001). Already Glaeser, et al. (1992, 1127) maintain that geographical proximity facilitates knowledge spillovers, because "intellectual breakthroughs must cross hallways and streets more easily than oceans and continents". This is followed up by Feldman \& Audretsch $(1999,410)$ who argue "knowledge spillovers not only generate externalities, but the evidence suggest that such knowledge spillovers tend to be geographically bounded".

In order to discuss the spatial knowledge spillovers, first of all, one needs to consider the main activities of firms. Firms are characterised by two main types of activities. First, ordinary production activities, i.e. at each point in time a firm uses current and fixed inputs to produce output by means of given techniques (routines). Second, development activities, i.e. the use by firms of part of the inputs to develop new types of outputs and/or new routines (including the development routines). It is essential to distinguish between these two types of activities, since knowledge spillovers have quite different effects in the two cases. Both ordinary production activities and development activities involve interaction with other firms and other economic agents - interactions that give rise to interaction costs, which increase with geographical distance between the actual firms and economic agents involved, and which are non-linear with regard to 
geographical distance (Johansson and Karlsson 2001). Hence, geographical proximity to other firms and economic agents brings an advantage to firms in particular when the interaction with them involves knowledge.

When it comes to type of knowledge that spillovers spatially, the prominent type is "technological knowledge", as supposed to scientific and entrepreneurial knowledge. This is mainly due to the fact that technological knowledge is "tacit" in nature, and hence face-to-face interaction in the spatially bounded space is required for the spillover of knowledge to occur (Arrow 1994). It should also be noted that the firm that developed new technological knowledge normally does not want to share it without compensation with competitors, so the knowledge-spillover in this case is unintentional.

When it comes to source of new knowledge, it is generated by firms and other economic agents through deliberate search for new knowledge in the form of R\&Dactivities and also through learning-by-doing. ${ }^{1}$ Inter-firm knowledge spillovers (and inter-economic agents in general) occur when the knowledge generated by one firm or economic agent is 'borrowed' by other firms and economic agents. Here, we must distinguish between spillovers between firms in the same sector (industry) and spillovers between firms in different sectors (Feldman and Audretsch 1999). One critical question here concerns whether the specific mix of economic activities undertaken within different regions matter for the extent and direction of knowledge spillovers, i.e. do knowledge spillovers occur mainly within or between sectors? This question, which concerns the recipients of knowledge spillovers, is very relevant and a debate among researchers during the two last decades has focused precisely on how the knowledge externalities, generated by knowledge spillovers, are affected by the regional mix of economic activities. Despite a consensus that knowledge spillovers within a given region stimulate dynamic knowledge externalities, there is no agreement concerning who the recipients of these knowledge spillovers are.

The seminal work in this literature is Glaeser et al. (1992), which analysed the factors that influence innovative activities in urban regions. The authors identify two relevant models in the economics literature. The first model is the so-called Marshall-ArrowRomer (MAR) model, which formalises the insight that the concentration of a particular sector within a specific urban region (Lösch 1954) promotes intra-regional knowledge spillovers across firms in that particular sector and therefore stimulates innovation in that particular industry. The basic assumption here is that knowledge spillovers, and thus knowledge externalities, mainly takes place across firms in the same sector.

The alternative view regards inter-sectoral knowledge spillovers as the most important channel to diffuse new economically relevant knowledge. Not least, Jacobs (1969 $\&$ 1984) argues that the agglomeration of firms from different sectors in urban regions fosters innovations due to the diversity of knowledge sources located in such regions. The recipients of knowledge spillovers from firms in one particular sectors are here firms in other sectors. The assumption here is that the variety of industries within an urban region can be a powerful engine of growth for that region, and that the exchange

\footnotetext{
${ }^{1}$ This search is directed towards different kinds of sources. The sources can be classified into two groups: i) sources containing embodied knowledge including individuals, firms, economic agents and products, and ii) sources containing disembodied knowledge, including books, articles, research, consultancy reports, patents, and web pages.
} 
of complementary knowledge across diverse firms leads to increasing returns to new knowledge (Tavassoli and Carbonara, 2014). However, the degree of inter-industry spillovers seems to be determined by the technological proximity between industries (Goto and Suzuki 1999; Verspagen 1997). However, we only have limited and sometimes contradictory empirical evidences concerning the impact of diversity on knowledge spillovers (Audretsch and Feldman 1999; van der Panne 2004).

To sum up this stream of literature, agglomeration externalities implies that firms can benefit from mutual proximity but whether a more specialised or a more diversified region is most favourable for existence and size of localised knowledge spillovers is still an open question (Rosenthal and Strange 2004). The empirical studies in the field give no clear answer to the question whether MAR or Jacobs's externalities are most important. While Henderson, Kunkoro \& Turner (1995) reach the conclusion that MAR externalities are most important, Boix and Trullén (2007) reach the opposite conclusion.

At the end, it is worthy to note that the gains from knowledge spillovers do not apply uniformly across firms in a region due to the heterogeneity among firms. They differ in terms of their absorptive capacity, history, age, size, knowledge and other resources, location, networks, ownership structure, routines, strategies and behaviour even if they belong to the same industry (Cohen and Levinthal 1990; Raspe and van Oort 2011). However, whether or not every firm can benefit equally from knowledge spillovers have received limited attention in the literature (Saito and Gopinath 2011).

\section{Aspatial knowledge spillovers}

As quoted earlier, Feldman \& Audretsch $(1999,410)$ stated that knowledge spillovers 'tend to be' geographically bounded. Such statement indicates that knowledge spillovers also may occur between regions. In fact, the authors themselves only five years later argued "there is no reason that knowledge stop spilling over just because of borders, such as a city limit, state limit or national boundary" (Audretsch and Feldman 2004 , 6). Here, it may be relevant to go back to Palander (1935), who observed that one of the most remarkable features of modern urban structures is the frequency and extension of the interactions between activities carried out in different cities. These interactions presuppose of course the possibility of communicating between cities. Possibilities that have multiplied many times since the 1930s due to, on the one hand, a telecommunications revolution that has lowered the marginal cost of information exchange between different locations to levels very close to zero, and, on the other hand, the evolution of highway and air travel networks that significantly has reduced the travel costs and the travel times. Thus, the inter-regional interaction costs have been reduced substantially in recent decades creating the necessary foundations for a global knowledge-intensive network economy (Karlsson 1994). Against this background, we may ask to what extent it is actually true that knowledge spillovers are limited in scope and spatial reach.

Indeed knowledge spillover can be also aspatial, i.e. either intra-firm or interregional. The intra-firm knowledge spillovers means knowledge can spillover form one organizational unit to another within a firm (Oldroyd and Gulati 2010; Ko and Liu 2015) or through alliance (Shu et al. 2014). While it is often implicitly assumed that internal knowledge is uniformly available to all firm units and internal knowledge 
spillovers is costless in the knowledge spillover research (Agarwal et al. 2010), more fine-grained research reports problems arising from for instance knowledge stickiness (Szulanski 1996) and costly transfer and interpretation processes (Oldroyd and Gulati 2010). Most research in this field is labelled knowledge transfer or knowledge spill-in (Villasalero 2013) as it often entails some conscious management offers to transfer knowledge from one organizational unit to another. One area with several studies concerns knowledge spill-ins in the form of learning effects experienced by one organizational unit which is then transferred to another organizational unit (Oldroyd and Gulati 2010; Villasalero 2013) in order to better interpret and respond to dynamic environments.

The aspatial knowledge spillovers can be also in the form of inter-regional. This can typically happen through the mechanism of formal networking, as noted in the previous section. An example of such formal networking is through formal research collaborations, which are usually not only inter-regional but also inter-national (Ponds et al. 2007; Hoekman et al. 2009). A prominent type of knowledge that is spillover interregionally (and internationally) is "scientific knowledge". The inter-regional scientific knowledge spillovers are indeed both substantial and rapid between individuals with the relevant absorptive capacity. The reason for this is that the international scientific community is organised in big knowledge networks, relying, for example, on international scientific conferences and journals and that rapid publication of new scientific results are important for the prestige of the individual scientists. Moreover, "entrepreneurship knowledge" in the form of business ideas also can diffuse between regions without major problems, since it normally is not proprietary, even if trademarks and logotypes can be protected. Thus, it might be the case that the claims that geographical knowledge spillovers tend to be geographically bounded underestimates the geographical reach of knowledge spillovers.

\section{The role of knowledge spillovers on strategic entrepreneurship}

Knowledge spillover is becoming one of the popular research streams in SE, as illustrated by the special issue in Strategic Entrepreneurship Journal (Agarwal et al. 2010). In this vein, the SE research is becoming dominated by issues regarding spatially bounded and inter-firm knowledge spillover mostly in the area of technological knowledge spillover (Gambardella and Giarratana 2010). Examples of studies in this field include Kotha's (2010) longitudinal case study on Boeings ability to use technological knowledge spillovers, especially in certain technical domains in military industry, to outmanoeuvre the competitor and market leader Douglas Aircraft Company. Technological knowledge spillover from defence industry into entrepreneurial startups has also been investigated by Plummer and Gilbert (2015).

As noted earlier, in principle, knowledge spillovers can be spatial, i.e. inter-firm knowledge spillovers within a same region, or it can be aspatial, i.e. either intra-firm or inter-region. Starting from spatial knowledge spillovers, we argue that this type of knowledge spillovers have mostly been acknowledged in previous research and studied in the resource/input part of SE. In particular, spatial knowledge spillovers have been described as a mechanism underlying the environmental munificence and as one of the most important environmental factors (Audretsch and Feldman 2004; Hitt 
et al. 2011). Such knowledge spillovers is the result of various types of interaction between the following categories of firms and other economic agents (von Hippel 1988): (i) the developer and other firms in the same trade, (ii) the developer and firms that are (potential) input suppliers, (iii) the developer and firms that are (potential) customers, (iv) the developer and commercial as well as non-commercial knowledge suppliers (including universities and research institutes), and (v) the developer and other firms belonging to the same multi-agent organization. In general, the SE research has recognized the importance of the spatial knowledge spillover perspective and several studies have been published in this area both for opportunity-seeking established firms such as Boeing (Kotha 2010) and advantage-seeking start-ups (Plummer and Gilbert 2015).

On the other hand, aspatial knowledge spillovers have been relatively neglected in the SE research compared to the spatial knowledge perspective as observed in the review of SE research. As discussed in the previous section, aspatial knowledge spillovers can be either inter-regional (inter-national) or intra-firm. First, if it is interregional, its effect on the dimension of SE is similar to spatial knowledge spillovers in a sense that here, again, the knowledge spillovers act as the knowledge input and hence can increase the amount of resource/input dimension of SE. The only difference here is that this inter-regional knowledge spillovers comes through the inter-regional and perhaps international networks and it is mostly in the form of scientific and technological knowledge between a few existing hot spots in a particular technology. Second, if the aspatial knowledge spillovers is intra-firm (e.g. between various units of a same firm located in the same/various countries), it mostly play a role in the resource orchestration processes part of SE, in particular in the resource bundling and leveraging processes. In particular, intra-firm knowledge spillovers can contribute to a better bundling of resources in a sense of combining the resources and capabilities in order to identify and exploit new opportunities as well as seeking competitive advantages (Hitt et al. 2011). Overall, SE research has a relative lack of studies of aspatial knowledge either inter-regional/inter-national or intra-firm. While there are many studies under the label of knowledge transfer (inter-regional, inter-national and intrafirm), which are relevant for SE research, they often lack the strategic perspective of advantage- or opportunity seeking and they often do not differentiate between knowledge which is compensated for, i.e., knowledge via the market, and knowledge which is unintentionally spillovered. Thus, there is a dearth of SE studies (both inter-regional and intra-firm) resulting in a relative lack of understanding of such phenomena. One of the few SE research examples of inter-national knowledge spillovers is the study by Liu et al. (2010) of Chinese firms founded by Chinese overseas returnees. Also intra-firm studies are rare; a recent example is Ko and Liu's (2015) study of internal knowledge spillover processes in social enterprises.

While knowledge spillovers does not play a direct role in affecting the outcome part of SE, it definitely affects outcome part of SE indirectly, through its effect on input and resource orchestration processes parts. The higher inter- and intra-firm knowledge spillovers, the higher input and more efficient resource orchestration processes, will presumably lead to higher intermediate outcomes (e.g. innovation) as well as final outcomes at the organizational level. For instance, if we consider product development and innovation activities, it is obvious that the information and knowledge that facilitate product development can be either generated within the firm (especially large firms 
with R\&D labs), i.e. intra-knowledge spillovers, or it may be exchanged (unintentionally or commercially) between the developer and other firms and economic agents, i.e. inter-firm knowledge spillovers. According to Hitt et al. (2011), output of SE could be divided into interim (innovation, new technologies) and ultimate (customer value, financial wealth, other benefits) and the benefits could be studied on the societal, organizational and individual level. Due to different methodological problems, such as problem of differentiating the source of knowledge for example in a newly developed product or problems getting access to internal company information, there are few studies in the area of output of SE disentangling the effects of knowledge spillover input, internal knowledge input and resource orchestration capabilities. Especially interesting, for our purposes, are studies of output as a function of different types of input, internal as well, spatial and aspatial knowledge spillover, and resource orchestration capabilities. One of the few relevant studies in this area is a study by Kotha (2010) describing and analysing the ascendancy of Boeing to an industry leadership in commercial aviation, as a function of knowledge spillover from the military industry, British, American and German, as well as from the competitors, both other American and British, as well as unique internal resources, e.g., their own wind tunnel, and spill-in, or resource orchestration, capabilities. The above discussion is shown in the following framework (Table 1) indicating the relative status of SEresearch. In general, the framework indicates a need for further SE-research using an aspatial knowledge spillover theoretical lens, both intra-firm and inter-regional/international.

\section{Conclusion}

In this paper we have theoretically discussed two main types of knowledge spillovers (by distinguishing it to be either spatial or aspatial) and then conceptually linked them to the three dimensions of SE. We argued that spatial knowledge spillovers (inter-firm) according to current SE-research play the major role in increasing the amount of resources/inputs dimension of SE. Moreover, we argued that aspatial knowledge (either inter-regional or intra-firm) could play at least as an important role not only for resources/inputs dimension, but also for resources orchestration dimension, however,

Table 1 State of SE research according to sources of knowledge spillovers and dimensions of SE

\begin{tabular}{lllll}
\hline & \multicolumn{2}{l}{ Dimensions of Strategic Entrepreneurship (SE) } \\
\cline { 3 - 5 } & & Resources & Resources orchestration & Output \\
\hline Knowledge Spillovers & Spatial & $\checkmark \checkmark$ & NA & $\checkmark$ \\
& $\begin{array}{l}\text { Aspatial } \\
\text { Inter-regional }\end{array}$ & $\checkmark$ & NA & $\checkmark$ \\
Aspatial & $\checkmark$ & $\checkmark$ & $\checkmark$ \\
& Intra-firm & & & $\checkmark$ \\
\hline
\end{tabular}

The sign " $\checkmark$ " indicates that a particular type of knowledge spillover (e.g. Spatial) has been studied previously, more frequently " $\checkmark \checkmark$ " or less frequently " $\checkmark$ " in the particular dimensions of SE (e.g. Resources). "NA" indicates Not Applicable 
it has been largely neglected by SE-research so far. Considering such "double" implication of aspatial knowledge spillovers for SE, we found the lack of theoretical framework and empirical evidence striking on aspatial knowledge spillovers already in knowledge spillovers literature, and also for SE. Hence here we provide few suggestions for future research.

First of all, the research in knowledge spillovers needs to pay more attention to aspatial knowledge spillovers (which can be either inter-regional or intra-firm). This will pave the way for a better understanding of the implication of this type of knowledge spillovers for SE. Moreover, future research needs to empirically investigate the three dimensions of SE, i.e. resources, resources orchestration, and output. This can be done in various ways. First, each of the dimensions can be separately investigated in a case study setting with a firm or a region as a unit of analysis. The analysis can also go beyond a case study and use large scale data on firms and regions. Second, the interrelation between the three dimensions can be investigated, once again both in a case study design or quantitative large scale data driven studies. Finally, the relation between types of knowledge spillovers and dimensions of SE (our proposed framework in the Table 1) can be tested empirically in various regions and countries.

Open Access This article is distributed under the terms of the Creative Commons Attribution 4.0 International License (http://creativecommons.org/licenses/by/4.0/), which permits unrestricted use, distribution, and reproduction in any medium, provided you give appropriate credit to the original author(s) and the source, provide a link to the Creative Commons license, and indicate if changes were made.

\section{References}

Agarwal, R., Audretsch, D., \& Sarkar, M. (2007). The process of creative construction: knowledge spillovers, entrepreneurship, and economic growth. Strategic Entrepreneurship Journal, 1(3/4), 263-286.

Agarwal, R., Audretsch, D., \& Sarkar, M. (2010). Knowledge spillovers and strategic entrepreneurship. Strategic Entrepreneurship Journal, 4, 271-283.

Ahlgren, K., Lagerstedt Wadin, J., \& Bengtsson, L. (2015). Characteristics of customer-side business models the case of solar energy deployment. Academy of Management Proceedings, 1, 14218.

Aldrich, H. (2000). Organizations evolving. Beverly Hills, CA: Sage.

Allen, T. J. (1977). Managing the flow of technology. Cambridge, MA: The MIT Press.

Alvesson, M., \& Kärreman, D. (2007). Constructing mystery: empirical matters in theory development. Academy of Management Review, 32, 1265-1281.

Archibugi, D., \& Coco, A. (2004). International partnerships for knowledge in business and academia. A Comparison between Europe and the USA, Technovation, 24, 517-528.

Archibugi, D., \& Lundvall, B.-Å. (2001). The Globalizing Knowledge Economy. Oxford: Oxford University Press.

Arrow, K. J. (1994). Methodological individualism and social knowledge. American Economic Association Papers and Proceedings, 84, 1-9.

Audretsch, D. B., \& Feldman, M. P. (1999). Innovation in cities: science-based diversity. Specialization and Localised Competition, European Economic Review, 43, 409-429.

Audretsch, D. B., \& Feldman, M. P. (2004). Knowledge spillovers and the geography of innovation. In J. V. Henderson \& J. F. Thisse (Eds.), Handbook of urban and regional economics (Vol. 4, pp. 2713-2739). Amsterdam: Elsevier.

Barney, J. B. (1991). Firm resources and sustained competitive advantage. Journal of Management, 17(1), 99120.

Baron, R. A., \& Henry, R. A. (2010). How entrepreneurs acquire the capacity to excel: insights from research on expert performance. Strategic Entrepreneurship Journal, 4(1), 49-65.

Baron, R. A., \& Tang, J. (2009). Entrepreneurs' social skills and new venture performance: mediating mechanisms and cultural generality. Journal of Management, 35(2), 282-306. 
Baum, J. R., \& Locke, E. A. (2004). The relationship of entrepreneurial traits, skill, and motivation to subsequent venture growth. Journal of Applied Psychology, 89(4), 587-598.

Boix, R., \& Trullén, J. (2007). Knowledge. Networks of Cities and Growth in Regional Urban Systems, Papers in Regional Science, 86, 551-575.

Boschma, R. A., \& Ter Wal, A. L. (2007). Knowledge networks and innovative performance in an industrial district: the case of a footwear district in the South of Italy. Industry and Innovation, 14(2), 177-199.

Boschma, R.A., R. Eriksson \& U. Lindgren (2009). How does labour mobility affect the performance of plants? The importance of relatedness and geographical proximity. Journal of Economic Geography, 9(2), 169-190.

Braunerhjelm, P., \& Ekholm, K. (1998). The geography of multinational firms. Boston, MA: Kluwer Academic Publishers.

Breschi, S., \& Lissoni, F. (2001). Localized knowledge spillovers vs. Innovative Milieux: Knowledge Tacitness Reconsidered, Papers in Regional Science, 80, 255-273.

Breschi, S., \& Lissoni, F. (2006). Mobility of inventors and the geography of knowledge spillovers. In New evidence on US data, CESPRI Working Paper 184. Milan: Bocconi University.

Bruyat, C., \& Julien, P. (2001). Defining the field of research in entrepreneurship. Journal of Business Venturing, 16, 165-180.

Burgelman, R. A. (1983). Corporate entrepreneurship and strategic management: insights from a process study. Management Science, 29, 1349-1364.

Cohen, W. M., \& Levinthal, D. A. (1990). Absorptive capacity: a new perspective on learning and innovation. Administrative Science Quarterly, 35, 128-152.

Covin, J. G., \& Slevin, D. P. (2002). The entrepreneurial imperatives of strategic leadership. In M. A. Hitt, R. D. Ireland, S. M. Camp, \& D. L. Sexton (Eds.), Strategic entrepreneurship: creating a new mindset (pp. 309-327). Oxford, UK: Blackwell Publishers.

Dana, L. P. (2001). Networks, internationalization \& policy. Small Business Economics, 16(2), 57-62.

Dodgson, M., Gann, D., \& Salter, A. (2006). The role of technology shift towards open innovation: the case of Procter \& Gamble. R\&D Management, 36(3), 333-346.

Eisenhardt, K. M., \& Martin, I. A. (2000). Dynamic capabilities: what are they? Strategic Management Journal, 21, 1105-1121.

Feldman, M. P., \& Audretsch, D. (1999). Innovation in cities: science-based diversity. Specialization and Localised Competition, European Economic Review, 43, 409-429.

Gambardella, A., \& Giarratana, M. S. (2010). Localized knowledge spillovers and skill-biased performance. Strategic Entrepreneurship Journal, 4, 323-339.

Glaeser, E. L., et al. (1992). Growth of cities. Journal of Political Economy, 100, 1126-1152.

Goto, A., \& Suzuki, K. (1999). R\&D capital. Rate of Return on R\&D Investment and Spillover of R\&D, Review of Economics and Statistics, 71, 555-564.

Grichnik, D., Brinckmann, J., Singh, L., \& Manigart, S. (2014). Beyond environmental scarcity: Human and social capital as driving forces of bootstrapping activities. Journal of Business Venturing, 29(2), 310-326.

Grossman, G. M., \& Helpman, E. (1994). Endogenous innovation in the theory of growth. Journal of Economic Perspectives, 8, 23-44.

Hannan, M. T., \& Freeman, I. H. (1989). Organizational ecology. Cambridge, MA: Harvard University Press.

Helfat, C. E., Finkelstein, S., Mitchell, W., Peteraf, M. A., Singh, H., Teece, D. J., \& Winter, S. (2007). Dynamic capabilities. Understanding dynamic change in organizations. Oxford: Blackwell.

Henderson, J. V. (1996). Ways to think about urban concentration: neoclassical Urban Systems versus the new economic geography. International Regional Science Review, 19, 31-36.

Hitt, M. A., Ireland, R. D., Camp, S. M., \& Sexton, D. L. (2001). Strategic entrepreneurship: entrepreneurial strategies for wealth creation. Strategic Management Journal, 22(6/7), 479-492.

Hitt, M. A., Ireland, R. D., Sirmon, D. G., \& Trahms, C. A. (2011). Strategic entrepreneurship: creating value for individuals, organizations, and society. Academy of Management Perspectives, 25, 57-75.

Hoekman, J., Frenken, K., \& van Oort, F. G. (2009). The geography of collaborative knowledge production in Europe. Annals of Regional Science, 43, 721-738.

Ireland, R. D., Hitt, M. A., Camp, S. M., \& Sexton, D. L. (2001). Integrating entrepreneurship and strategic management actions to create wealth. Academy of Management Executive, 15(1), 49-63.

Ireland, R. D., Hitt, M. A., \& Sirmon, D. G. (2003). A model of strategic entrepreneurship: the construct and its dimensions. Journal of Management, 29(6), 963-989.

Jacobs, J. (1969). The economy of cities. New York: Random House.

Johansson, B., \& Karlsson, C. (2001). Geographic transaction costs and specialisation opportunities of small and medium-sized regions: scale economies and market extension. In B. Johansson, C. Karlsson, \& R. R. 
Stough (Eds.), Theories of endogenous regional growth (pp. 150-180). Springer, Berlin: Lessons for Regional Policies.

Karlsson, C. (1988), Innovation Adoption and the Product Life Cycle, Umeå University, Umeå (diss.)

Karlsson, C. (1994). From knowledge and technology networks to network technology. In B. Johansson, C. Karlsson, \& L. Westin (Eds.), Patterns of a network economy (pp. 207-228). Berlin: Springer-Verlag.

Karlsson, C., \& Manduchi, A. (2001). Knowledge spillovers in a spatial context - a critical review and assessment. In M. Fischer \& J. Frölich (Eds.), Knowledge (pp. 101-123). Springer, Heidelberg: Complexity and Innovation Systems.

Karlsson, C., \& Tavassoli, S. (2016). Innovation strategies of firms: what strategies and why? The Journal of Technology Transfer, 1-24. doi:10.1007/s10961-015-9453-4.

Keats, B. W., \& Hitt, M. A. (1988). A causal model of linkages among environmental dimensions, macro organizational characteristics, and performance. Academy of Management Journal, 31(3), 570-598.

Ketchen, D. J., Ireland, R. D., \& Snow, C. C. (2007). Strategic entrepreneurship, collaborative innovation, and wealth creation. Strategic Entrepreneurship Journal, 1(3-4), 371-385.

Kleinbaum, A. M., \& Tushman, M. L. (2007). Building bridges: the social structure of interdependent innovation. Strategic Entrepreneurship Journal, 1(1-2), 103-122.

Kline, S. J., \& Rosenberg, N. (1986). An overview of innovation. In R. Landau \& N. Rosenberg (Eds.), The positive sum strategy: harnessing Technology for Economic Growth (pp. 275-305). Washington, D.C.: National Academy press.

Ko, W. W., \& Liu, G. (2015). Understanding the process of knowledge spillovers: learning to become social enterprises. Strategic Entrepreneurship Journal, 9, 263-285.

Kotha, S. (2010). Spillovers, spill-ins, and strategic entrepreneurship: America's first commercial jet airplane and Boeing's ascendancy in commercial aviation. Strategic Entrepreneurship Journal, 4, 284-306.

Kuratko, D. F., \& Audretsch, D. B. (2009). Strategic entrepreneurship: exploring different perspectives of an emerging concept. Entrepreneurship: Theory and Practice, 33(1), 1-17.

Larsson, R., Bengtsson, L., Henriksson, K., \& Sparks, J. (1998). The interorganizational learning dilemma: collective knowledge development in strategic alliances. Organization Science, 9(3), 285-305.

Light, I., \& Dana, L. P. (2013). Boundaries of social capital in entrepreneurship. Entrepreneurship: Theory and Practice, 37(3), 603-624.

Li, H., de Zubielqui, G. C., \& O’Connor, A. (2015). Entrepreneurial networking capacity of cluster firms: a social network perspective on how shared resources enhance firm performance. Small Business Economics, 45(3), 523-541.

Liu, X., Wright, M., Filatotchev, I., Dai, O., \& Lu, J. (2010). Human mobility and international knowledge spillovers: evidence from high-tech small and medium enterprises in an emerging market. Strategic Entrepreneurship Journal, 4, 340-355.

Lösch, A. (1954). The economics of location. New Haven, CT: Yale University Press.

Mannor, M. J., Shamsie, J., \& Conlon, D. E. (2016). Does experience help or hinder top managers? Working with different types of resources in Hollywood. Strategic Management Journal, 37, 1330-1340.

McGahan, A. M., Zelner, B. A., \& Barney, J. B. (2013). Entrepreneurship in the public interest: introduction to the special issue. Strategic Entrepreneurship Journal, 7, 1-5.

McGrath, R. G., \& MacMillan, I. C. (2000). The entrepreneurial mindset. Boston: Harvard Business School Press.

Mckelvey, M., Alm, H., \& Riccaboni, M. (2003). Does Co-location matter for formal knowledge collaboration in the Swedish biotechnology-pharmaceutical sector? Research Policy, 32, 483-501.

Meyer, G. D., \& Heppard, K. A. (2000). Entrepreneurship as strategy: competing on the entrepreneurial edge. Thousand Oaks: Sage Publications.

Mihalache, O. R., Jansen, J. J., Van den Bosch, F. A., \& Volberda, H. W. (2014). Top management team shared leadership and organizational ambidexterity: A moderated mediation framework. Strategic Entrepreneurship Journal, 8(2), 128-148.

Miller, D., Xu, X., \& Mehrotra, V. (2015). When is human capital a valuable resource? The performance effects of Ivy League selection among celebrated CEOs. Strategic Management Journal, 36(6), 930-944.

Mintzberg, H. M., \& Waters, J. A. (1982). Tracking strategy in an entrepreneurial firm. Academy of Management Journal, 25(s), 465-499.

Oldroyd, J. B., \& Gulati, R. (2010). A learning perspective on intraorganizational knowledge spill-ins. Strategic Entrepreneurship Journal, 4, 356-372.

Palander, T. (1935). Beiträge zur Standorttheorie. Uppsala: Almqvist \& Wicksell.

Park, H. D., \& Steensma, H. K. (2013). The selection and nurturing effects of corporate investors on new venture innovativeness. Strategic Entrepreneurship Journal, 7, 311-330. 
Plummer, L. A., \& Gilbert, B. A. (2015). The effect of defense agency funding of university research on regional new venture creation. Strategic Entrepreneurship Journal, 9, 136-152.

Ponds, R., van Oort, F. G., \& Frenken, K. (2007). The geographical and institutional proximity of research collaboration. Papers in Regional Science, 86, 423-443.

Porter, M. (1990). The competitive advantage of nations. London: Macmillan.

Raspe, O., \& van Oort, F. G. (2011). Firm heterogeneity. Productivity and Spatially Bounded Knowledge Externalities, Socio-Economic Planning Sciences, 45, 38-47.

Ratten, V. (2014). Future research directions for collective entrepreneurship in developing countries: a small and medium-sized enterprise perspective. International Journal of Entrepreneurship and Small Business, 22(2), 266-274.

Ratten, V., \& Suseno, Y. (2006). Knowledge development, social capital and alliance learning. International Journal of Educational Management, 20(1), 60-72.

Rosenthal, S. S., \& Strange, W. C. (2004). Evidence on the nature and sources of agglomeration economies. In J. V. Henderson \& J. F. Thisse (Eds.), Handbook of regional and urban economics: cities and geography (pp. 2119-2179). Amsterdam: North Holland.

Saito, H., \& Gopinath, M. (2011). Knowledge spillovers. Absorptive Capacity, and Skill Intensity of Chilean Manufacturing Plants, Journal of Regional Science, 51, 83-101.

Shane, S., \& Venkataraman, S. (2000). The promise of entrepreneurship as a field of research. Academy of Management Review, 25(1), 217-226.

Shepherd, D. A., Patzelt, H., \& Haynie, J. M. (2009). Entrepreneurial spirals: deviation-amplifying loops of an entrepreneurial mindset and organizational culture. Entrepreneurship: Theory and Practice, 33(1), 1-24.

Shu, C., Liu, C., Gao, S., \& Shanley, M. (2014). The knowledge spillover theory of entrepreneurship in alliances. Entrepreneurship: Theory and Practice, 38, 913-940.

Sood, A., \& Tellis, G. J. (2005). Technological evolution and radical innovation. Journal of Marketing, 69(3), $152-168$.

Suseno, Y., \& Ratten, V. (2007). A theoretical framework of alliance performance: the role of trust, social capital and knowledge development. Journal of Management \& Organization, 13(01), 4-23.

Szulanski G. (1996) Exploring internal stickiness: impediments to the transfer of best practice within the firm. Strategic Management Journal 17(Winter Special Issue): 27-43.

Tavassoli, S., \& Carbonara, N. (2014). The role of knowledge variety and intensity for regional innovation. Small Business Economics, 43(2), 493-509.

Tavassoli, S., \& Karlsson, C. (2015a). Persistence of various types of innovation analyzed and explained. Research Policy, 44(10), 1887-1901.

Tavassoli, S., \& Karlsson, C. (2015b). Innovation strategies and firm performance: simple or complex strategies? Economics of Innovation and New Technology, 1-20. doi:10.1080/10438599.2015.1108109.

Teece, D. J. (2007). Explicating dynamic capabilities: the nature and microfoundations of (sustainable) enterprise performance. Strategic Management Journal, 28(13), 1319-1350.

Tocher, N., Oswald, S. L., \& Hall, D. J. (2015). Proposing social resources as the fundamental catalyst toward opportunity creation. Strategic Entrepreneurship Journal, 9, 119-135.

van der Panne, G. (2004). Agglomeration externalities: Marshall versus Jacobs. Journal of Evolutionary Economics, 14, 593-604.

Verspagen, B. (1997). Estimating international technology spillovers using technology flow matrices. Weltwirtschaftliches Archiv, 133, 226-248.

Villasalero, M. (2013), Signaling, spillover and learning effects of knowledge flows on division performance within related diversified firms, Journal of Knowledge Management, Vol. 17 Iss: 6, pp. 928-942

von Hippel, E. (1988). The sources of innovation. Oxford: Oxford University Press.

von Hippel, E. (2005). Democratizing innovation: the evolving phenomenon of user innovation. Journal für Betriebswirtschaft, 55(1), 63-78.

Winter, S. G. (2005). Developing evolutionary theory for economics and management. In K. G. Smith \& M. A. Hitt (Eds.), Great minds in management (pp. 509-546). Oxford, UK: Oxford University Press.

Yang, H., \& Steensma, K. (2014). When do firms rely on their knowledge spillover recipients for guidance in exploring unfamiliar knowledge? Research Policy, 43(9), 1496-1507.

Zhang, C., Wu, F., \& Henke, J. W. (2015). Leveraging boundary spanning capabilities to encourage supplier investment: a comparative study. Industrial Marketing Management, 49, 84-94. 